\title{
FINITE ELEMENT ANALYSIS AND FULL-SCALE TESTING OF LOCOMOTIVE CRASHWORTHY COMPONENTS
}

\author{
Patricia Llana \\ Volpe National Transportation Systems Center \\ US Department of Transportation \\ Cambridge, MA 02142 USA
}

\author{
Richard Stringfellow \\ TIAX LLC \\ Lexington, MA 02421 USA
}

\author{
Ronald Mayville \\ Simpson Gumpertz \& Heger Inc. \\ Waltham, MA 02453 USA
}

\begin{abstract}
The Office of Research and Development of the Federal Railroad Administration (FRA) and the Volpe Center are continuing to evaluate new technologies for increasing the safety of passengers and operators in rail equipment. In recognition of the importance of override prevention in train-totrain collisions in which one of the vehicles is a locomotive, and in light of the success of crash energy management technologies in cab car-led passenger trains, the Volpe Center seeks to evaluate the effectiveness of components that could be integrated into the end structure of a locomotive that are specifically designed to mitigate the effects of a collision and, in particular, to prevent override of one of the lead vehicles onto the other. A research program has been conducted to develop, fabricate and test two crashworthy components for the forward end of a locomotive: (1) a deformable anti-climber, and (2) a push-back coupler. Detailed designs for these components were developed, and the performance of each design was evaluated through large deformation dynamic finite element analysis (FEA). Designs for two test articles that could be used to verify the performance of the component designs in fullscale tests were also developed. The two test articles were fabricated and dynamically tested by means of rail car impact in order to verify certain performance characteristics of the two components relative to specific requirements. The tests were successful in demonstrating the effectiveness of the two design concepts. Test results were consistent with finite element model predictions in terms of energy absorption capability, forcedisplacement behavior and modes of deformation.
\end{abstract}

\section{INTRODUCTION}

In the event of a collision between two trains, a considerable amount of energy must be dissipated. One of the potential consequences of such a collision is override of one of the vehicles onto the other. Locomotives, because of their great longitudinal strength and stiffness, are particularly susceptible to override when they collide with another vehicle, and the consequences can be catastrophic. Research has shown that conventional anti-climbing structures can deform on impact and form a ramp, increasing the likelihood of override [1]. As they crush longitudinally, conventional anti-climbers lose their vertical load carrying capacity due to the substantial fracture that occurs as the anti-climber crushes. The longitudinal crush of the anti-climber causes fracture in the webs behind the face of the anti-climber. These fractured webs can still resist a longitudinal compression load, but can no longer transmit a vertical shear load. This loss of vertical load-carrying capacity in conventional anti-climbers often leads to ramp formation, which promotes override. Such behavior was exhibited in a 23mph collision that occurred in Red Oak, Iowa on April 17, 2011 [2].

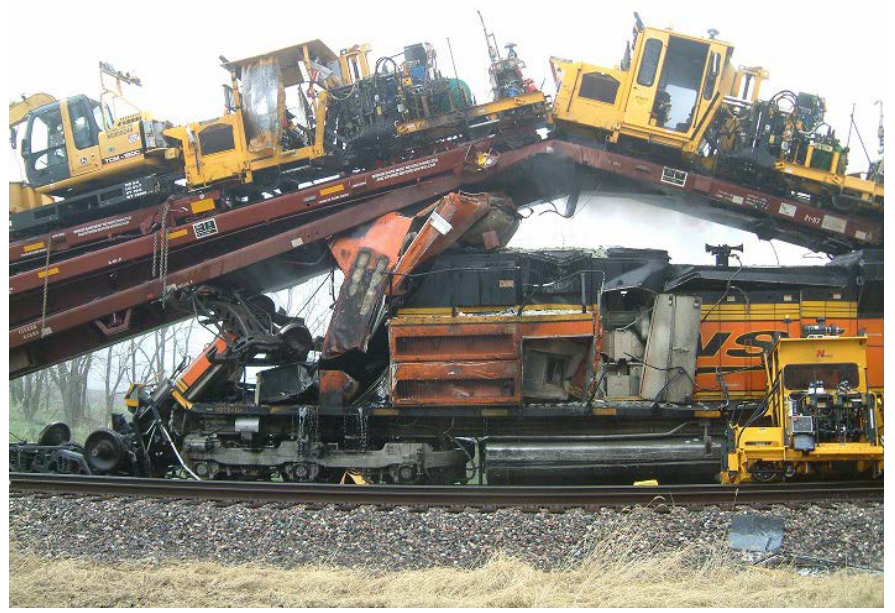

Figure 1. Red Oak, Iowa Collision, April 17, 2011

This material is declared a work of the U.S. Government and is not subject to copyright protection in the United States. Approved for public release; distribution is unlimited. 
As seen in Figure 1, the accident resulted in several maintenance-of-way equipment cars overriding the impacting locomotive. The photograph shows the impacting locomotive's modular crew cab was detached and partially crushed as a result of being overridden, resulting in two fatalities. In order to be effective, an anti-climber must engage the end structures of opposing equipment and provide sufficient vertical load carrying capacity to prevent such override.

Research has also shown that the addition of a few structural features to the forward end of a locomotive can greatly reduce the propensity for override [3]. These features include the following:

1. Push-back couplers, and

2. Deformable anti-climbers.

Push-back couplers allow the ends of the vehicles to engage prior to the build-up of large forces and moments that might lead to lateral buckling of the vehicles with respect to one another. Deformable anti-climbers provide sufficient vertical load carrying capacity as they deform gracefully and predictably to prevent the formation of a ramp. Crushable zones within deformable anti-climbers absorb collision energy so as to prevent uncontrolled deformation of interlocking features that might cause formation of a ramp.

Structural features such as these that are specifically put in place to mitigate the effects of a collision are common in rail vehicles that are designed according to the principles of crash energy management (CEM). CEM is a design strategy aimed at increasing occupant survivability during a collision, and is based on the notion that the energy of a collision can be dissipated in a controlled manner through the use of crush zones and other structural features. The Volpe Center is supporting the Office of Research and Development of the FRA in the development of a CEM system for locomotives. In a previous research program, the Volpe Center developed several concepts for a more crashworthy locomotive [3]. The study addressed the feasibility of incorporating push-back couplers and deformable anti-climbers into locomotives. Conceptual design goals included the preservation of occupant volume and the maintenance of vehicle-rail contact, i.e., the prevention of override, while ensuring that the equipment was compatible with existing operating requirements. Building on this previous work, the objectives of a recently completed research program were to: (1) develop detailed designs for a push-back coupler and a deformable anti-climber; (2) develop test article designs for the components; (3) construct the test articles; (4) conduct the component tests; and (5) if necessary, refine the designs based on the results of the tests. This is an ongoing program. The development of the component designs is detailed in a companion paper [4]. The finite element analyses of the component designs are detailed in a second companion paper [5]. This paper describes the sub-component analyses and tests, the design and analyses of the full-scale test articles, and the full-scale dynamic tests. The results of the dynamic tests are then compared to the design requirements and the pre-test finite element predictions to see how well the crashworthy component designs performed.
The overridden locomotive involved in the Red Oak accident was compliant with the latest regulations, specifically AAR S-580 [6]. When these regulations were adopted, pushback couplers and deformable anti-climbers were discussed, but the technology was not sufficiently mature. This research program endeavored to develop this technology further.

\section{DESIGN REQUIREMENTS}

The first phase of the research program was aimed at defining design requirements for a platform-style locomotive with increased crashworthiness due to the incorporation of a pushback coupler and a deformable anti-climber. These requirements govern the development of designs for such components, and include collision scenarios for evaluating their behavior in a collision with another vehicle. The design requirements are comprised of performance requirements, geometric requirements, operational requirements, and fabrication requirements. The energy absorption requirements and many of the other crashworthiness specifications are derived from experience gained in other crashworthiness programs. Most of the strength requirements and some of the crashworthiness specifications are derived from the APTA [7] and AAR [6] standards. All of the requirements are consistent with CFR 49, Part 229 [8], APTA SS-C\&S-034-99, Rev 2 [7], and APTA RP-C\&S-XXX [9]. During the development process, the design requirements evolved as the designs were evaluated. In the interest of efficiency, the final design requirements can be found in the most recent companion paper [5].

\section{COMPONENT DESIGNS Push-back Coupler}

The specific locomotive platform chosen for development is a MotivePower MPXpress MP40PH-3C. The design for the pushback coupler employs an H-type coupler attached to a pushback yoke and deformation tube. Figure 2 shows a view from below of the push-back coupler inside the draft gear pocket of the locomotive.

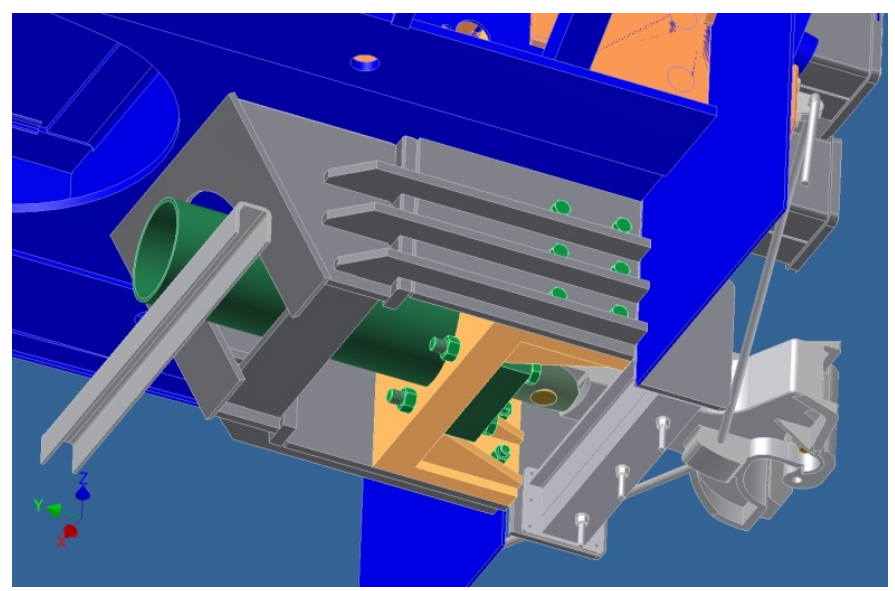

Figure 2. View of the shear bolts (green) that attach the push-back coupler to the sides of the draft gear pocket

This material is declared a work of the U.S. Government and is not subject to copyright protection in the United States. Approved for public release; distribution is unlimited. 
The draft gear pocket has been redesigned to provide more than 10 inches of additional stroke. The push-back coupler is attached to the draft gear pocket by the coupler support assembly (shown in yellow in Figure 2) with 12 shear bolts, six on each side. The six shear bolts on the right side are shown in Figure 2 in green. These bolts are designed to fail at a total load of approximately 1,000,000 lbf once the energy-absorbing stroke of the push-back coupler has been exhausted, thereby shifting the load path from the push-back coupler to the deformable anti-climber.

After the shear bolts fail, the entire coupler support assembly, or 'sliding lug', slides back, so that the load through the coupler is effectively zero. As is shown in Figure 2, the back of the draft pocket has structure built into it that will capture the sliding lug after 10 additional inches of push-back.

\section{Deformable Anti-climber}

The design for the deformable anti-climber employs four progressive buckling tubes (crush tubes) welded onto the front plate of the locomotive: two tubes located at the base of the short hood, and two tubes located beneath them. Figure 3 shows a detailed view of the deformable anti-climber/pushback coupler system.

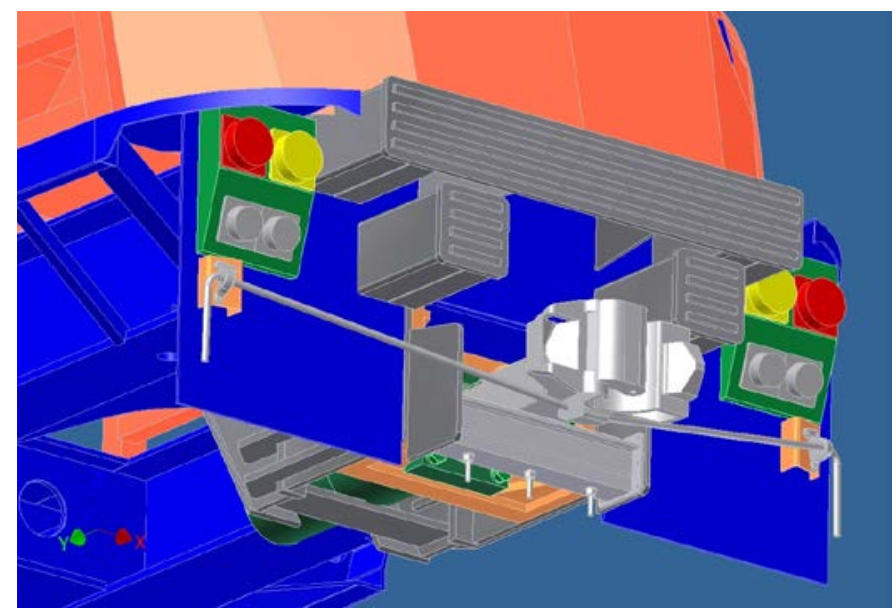

Figure 3. Detailed view of the deformable anticlimber/push-back coupler system

In a collision with a conventional locomotive, the upper crush tubes are designed to interact with heavy gussets that are welded to the front plate of the locomotive as part of the conventional anti-climber. The upper crush tubes are connected laterally by a ribbed front plate. This plate is designed to resist the upward motion of the coupler of a colliding vehicle to help prevent override. Together with the upper set of crush tubes, it is designed to withstand a 100,000 lbf vertical load at any time during the crush process. In the event of a collision with a cab car, this plate also interacts with the collision posts at the end of the cab car, allowing the upper crush tubes to absorb energy. The lower set of crush tubes is designed to interact with the buffer beam of a colliding cab car. In a collision with a conventional locomotive, these tubes do not participate in the early stages of the collision. In a collision with a center beam flat car-type freight car, neither set of tubes participates in the early stages of the collision. Eventually, they interact with the bulkhead of the freight car. Support structures have been added between the two main longitudinal beams of the underframe for the purpose of transferring impact loads into the underframe.

\section{FINITE ELEMENT MODELS \& ANALYSES}

Finite element (FE) meshes were constructed for the conventional and modified locomotives, a cab car, and a freight locomotive. A description of the FE meshes can be found in the second companion paper [5]. These meshes were appropriately combined to form the FE models for the three collision scenarios described in the design requirements and explained in the second companion paper [5]. The FE models were evaluated through large deformation dynamic finite element analyses. The component designs were found to meet all of the design requirements. Both component designs met their deformation mode and energy absorption requirements. There was no ramp formation or uncontrolled deformation in the modified or conventional vehicles, and, of particular importance, there was no override of one vehicle onto another in any of the collision scenario cases.

\section{DESCRIPTION OF TEST ARTICLES \& MODELS}

Designs for two test articles that could be used to verify the performance of the component designs in full-scale tests were then developed. Finite element models of the test articles were constructed and analyses were performed to generate predictions of the performance of the test articles.

\section{Push-back Coupler}

The push-back coupler test article model is pictured in Figure 4. It comprises a support assembly that features two I-beams that are welded to a large back plate and reinforced with triangular gussets. A top plate is bolted across the top flanges of the Ibeams and a bottom plate is welded between the bottom flanges. Side plates are welded to the bottoms of the I-beams and reinforced with horizontal stiffener plates. A front plate and two sets of gussets (one vertical and one angled back) provide further stiffness to the support assembly.

The push-back coupler test article features a push-back coupler designed and manufactured by Voith Turbo. Elastomeric elements provide reversible energy absorption for low speed impacts. A deformation tube provides irreversible energy absorption for higher speed impacts. On compression, an element attached to the inboard end of the coupler moves against the elastomeric elements. With enough stroke and load, this piece eventually causes the deformation tube to activate. The moving piece has an outer diameter that is larger than the inner diameter of the deformation tube. The push-back force is created by interference between the elements and the tube material. The stroke over which energy is absorbed depends on the tube length, and is therefore customizable.

The force-displacement characteristics of the push-back coupler used in this program are as follows: the load builds up

This material is declared a work of the U.S. Government and is not subject to copyright protection in the United States. Approved for public release; distribution is unlimited. 
nearly linearly from zero to 3,000 $\mathrm{kN}(674,400 \mathrm{lbf})$ over about $75 \mathrm{~mm}$ (3 inches) as a rubber spring compresses. With additional stroke, the deformation tube activates and the load stays effectively constant at $674,000 \mathrm{lbf}$ throughout the stroke of the deformation tube.

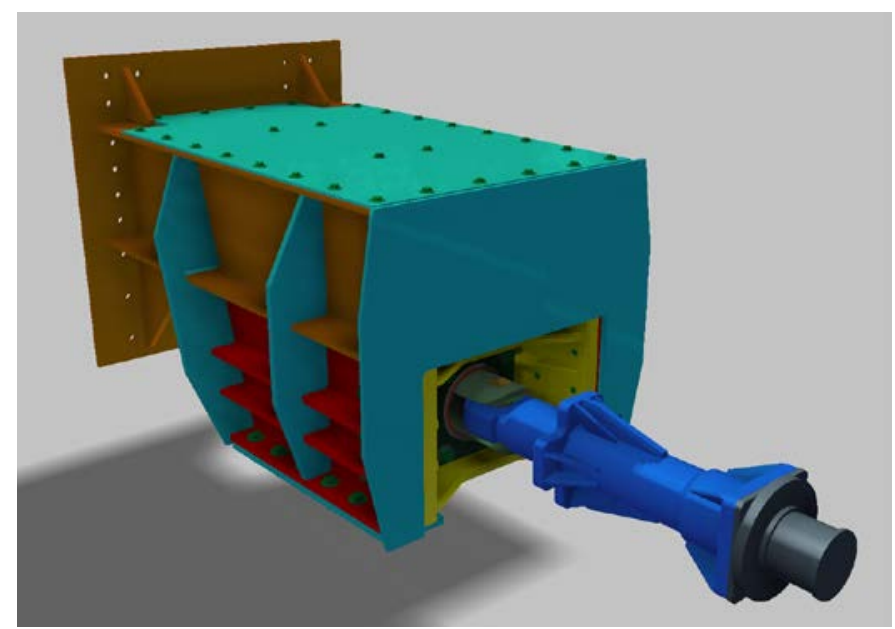

Figure 4. The push-back coupler test article

The push-back coupler is mounted to a sliding lug assembly (indicated in yellow in Figure 4), that is in turn bolted to the side plates using 12 specially-designed shear bolts. A coupler extension (shown in blue) is connected to the coupler through use of a standard coupler pin arrangement. A feature has been added to the coupler extension so that, when the total stroke of the coupler reaches 18” (457 mm), the back surface of the feature will impact the front surface of the sliding lug mounting block, thereby causing the load to spike and shear off the bolts. Once the bolts have broken, there is no further mechanism of energy absorption, and the force drops to zero.

The shear bolts have been designed so that they break at a design load of $12 \times 88$ kips = 1,056 kips $(4,700 \mathrm{kN})$. A detail from a drawing that shows the shear bolt connection arrangement is pictured in Figure 5(a). A shear bolt is pictured in Figure 5(b) together with its two bushings. The front of the extension is bolted to a 'tup' — a 6-inch round cylindrical impactor that is slightly rounded at its forward end and includes a 5,000 kN (1,125 kips) load cell. The push-back coupler test article weighs approximately $6,600 \mathrm{lbs}$.

\section{Deformable Anti-climber}

The deformable anti-climber test article model, pictured in Figure 6, consists of four crush tubes mounted onto a large, thick back plate that is designed, in turn, to be mounted directly to an instrumented test wall. The two upper crush tubes are positioned 12.5 inches above the lower crush tubes. They are connected by a 68 -inch wide $\times 11$-inch high $\times 1$.0-inch thick front plate that has four 0.5-inch thick $\times 1$.0-inch high $\times 66$ inch long bars, centered vertically 2.5 inches apart from one another, welded to its front surface. The two lower crush tubes are two inches longer than the two upper crush tubes, and spaced closer together laterally (38.5 inches center-to-center vs. 57 inches center-to-center for the upper tubes). Each tube has its own 11-inch square $\times 1$ 1.0-inch thick front plate, with a similar set of four bars welded to it, each 0.5 -inch thick $\times 1.0$ inch high $\times$ 9-inch long, spaced at 2.5-inch intervals.

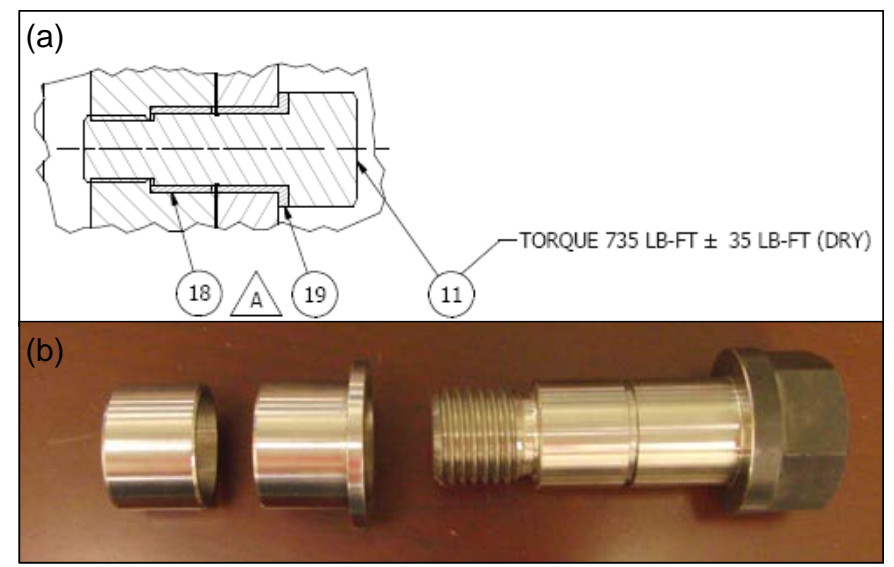

Figure 5. (a) a drawing detail showing the shear bolts installed through the walls of the side plate assembly and the sliding lug assembly; (b) a photograph of a shear bolt and its two bushings. (Shear bolts were designed and manufactured by Voith Turbo.)

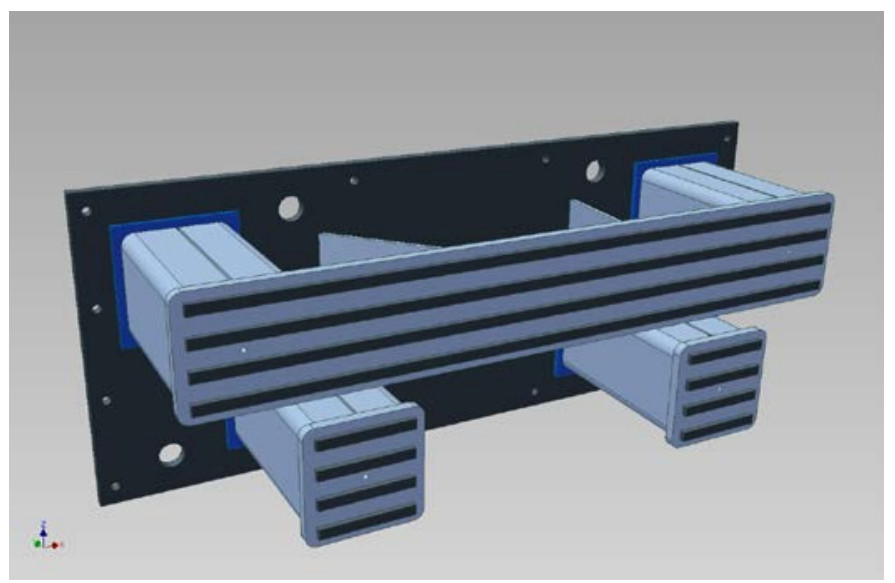

Figure 6. The deformable anti-climber test article

Each of the tubes has a 0.25 -inch wall thickness. In addition, each tube has four rounded, 0.125 -inch deep slots cut into it to promote controlled folding: two on the inside and two on the outside. The two inside slots are cut into the sides of the tubes, and the two outside slots are cut into the top and bottom of the tubes, across the welded seam that joins the two halves of each tube. The slots are centered about 2.375 inches from the front of each tube.

In addition to the four crush tubes, there are two 0.5-inch thick angled support plates that provide stability and vertical strength to the upper set of crush tubes. These are oriented vertically and positioned approximately 17 inches away from one another where they are welded to the front plate and 28.75 inches away from one another where they are welded to the

This material is declared a work of the U.S. Government and is not subject to copyright protection in the United States. Approved for public release; distribution is unlimited. 
back plate. The deformable anti-climber test article weighs approximately 1,275 lbs. This includes the fixture back plate.

\section{PRELIMINARY TESTS}

Preliminary material tests and quasi-static crush tube tests were conducted at Simpson Gumpertz \& Heger Inc. (SGH) in Waltham, Massachusetts. A series of tensile tests were conducted to determine the stress-strain behavior, through fracture, of the specific lot of A572-50 steel that would later be used to fabricate both the deformable anti-climber and the push-back coupler test articles. The material testing was critical in modeling the material behavior and failure in the $\mathrm{FE}$ analyses.

Given uncertainties regarding the crush performance of the crush tube components of the deformable anti-climber due to the uniqueness of the slotted tube design, quasi-static tests on individual crush tubes were conducted to evaluate their performance. Conducting the crush tube tests provided an opportunity to test and refine the design of the tubes prior to the dynamic test. It was determined from these tests that a fourslotted tube design was effective in promoting controlled folding as well as limiting the magnitude of the load peak that arises shortly after an impact.

\section{FULL-SCALE TESTS \& RESULTS}

Full-scale dynamic testing was conducted at TÜV SÜD Rail GmbH, in Görlitz, Germany. For both the push-back coupler and deformable anti-climber tests, six accelerometers were mounted onto the impact rail car. There were two sets of three accelerometers. Each set consisted of one accelerometer in each of the three directions: longitudinal, vertical, and lateral. The two sets were mounted on the same (left) side of the car, one in the front and one in the rear, as is illustrated in Figure 7. For all of the impact tests, the data from the accelerometers were used to confirm the data from the load cells. The load cells are described in the following sections.

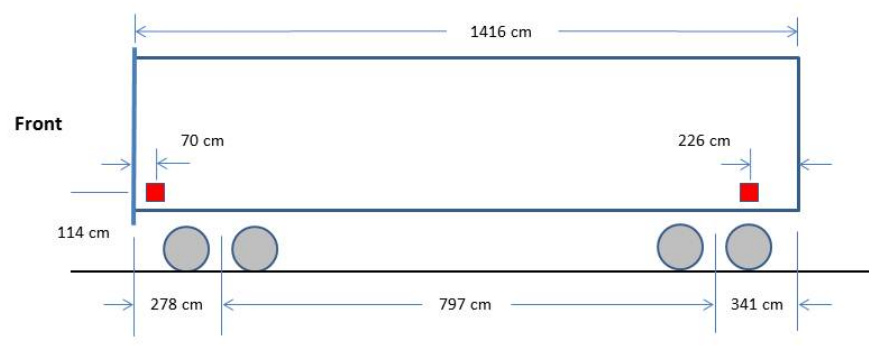

Figure 7. The positions of the accelerometer sets on the impact rail car

\section{Push-back Coupler}

Figure 8 shows an illustration of the test configuration for the push-back coupler test. Figure 9 shows a photograph of the mounted test article. It was mounted to the impacting rail car and has an extension piece that represents an actual coupler shank. There was a load cell mounted on the end of this extension piece, which impacts the end plate of the test wall load cell system with a steel ring welded to it that limits lateral motion should it occur. The extension piece is normally not restricted from rotating about the coupler pin. It was supported both vertically and laterally by straps to prevent it from moving significantly prior to impact, as shown in Figure 10. These straps did not interfere with the push-back motion of the extension and coupler. Energy absorbing buffers were mounted on the sides of the test article on both the rail car and the crash wall to absorb residual energy if required.

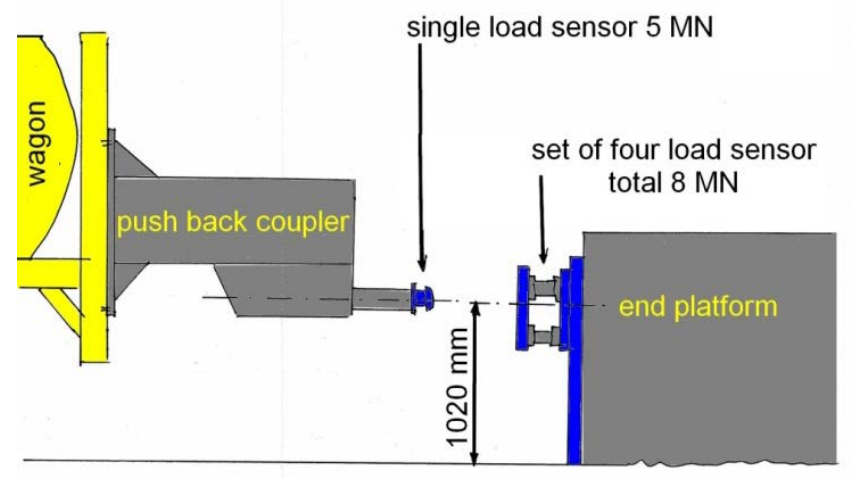

Figure 8. An illustration of the push-back coupler configuration

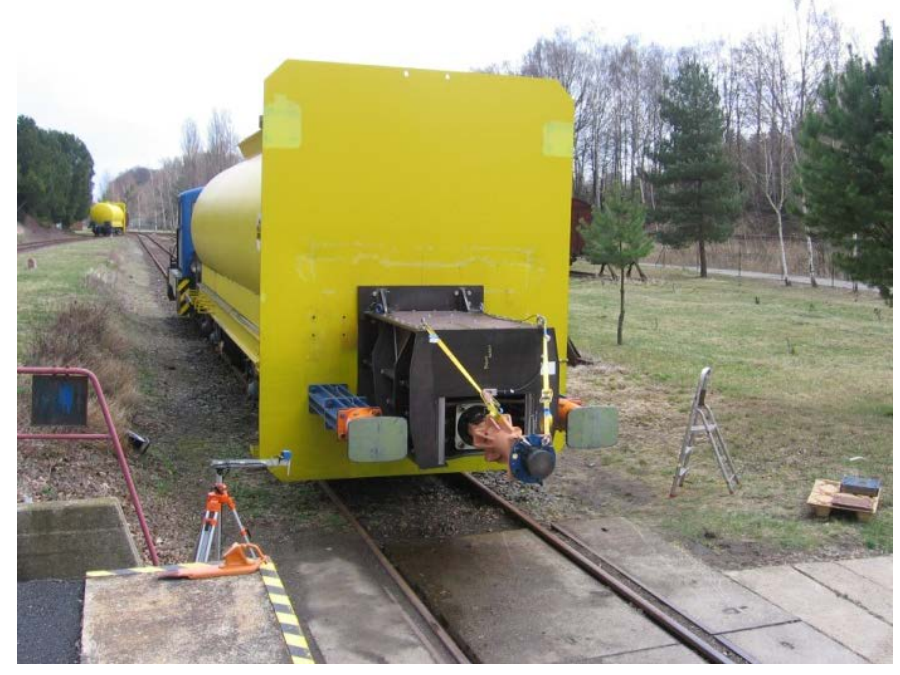

Figure 9. A photograph of the push-back coupler test article mounted on the impact car

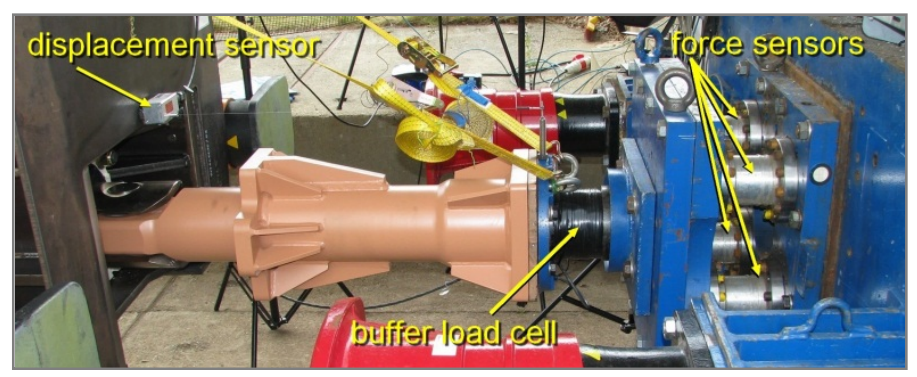

Figure 10. A photograph showing the push-back coupler extension piece supporting straps

This material is declared a work of the U.S. Government and is not subject to copyright protection in the United States. Approved for public release; distribution is unlimited. 
Two impacts were required to complete the push-back coupler test. The speed of the rail car in the first impact was $19.9 \mathrm{~km} / \mathrm{hr}(12.4 \mathrm{mph})$, which was below the target impact velocity of $23.5 \mathrm{~km} / \mathrm{hr}$ as well as below the minimum expected impact speed of $21.5 \mathrm{~km} / \mathrm{hr}$. Because the initial kinetic energy associated with this impact speed (10,800 in-kips) was slightly less than the energy required to exhaust the deformation tube (11,100 in-kips), there was insufficient energy to fail the shear bolts. For this reason, a second impact was made, with a target speed $(11 \mathrm{~km} / \mathrm{hr})$ chosen so as to provide enough energy to exhaust the remaining very small extent of deformation tube stroke and completely fail the shear bolts. For this second impact, the measured impact speed was $11.9 \mathrm{~km} / \mathrm{hr}$. The shear bolts all failed, and the sliding lug moved approximately 10 inches into its pocket.

Figure 11 shows that the deformation tube has been essentially exhausted after the first impact. Lubrication ports that extend outward about 0.5 -inch from the coupler mounting block were partially crushed, indicating that the back plate of the coupler extension had just made contact in the first impact. This is consistent with the 18 in. stroke measured for this part of the test.

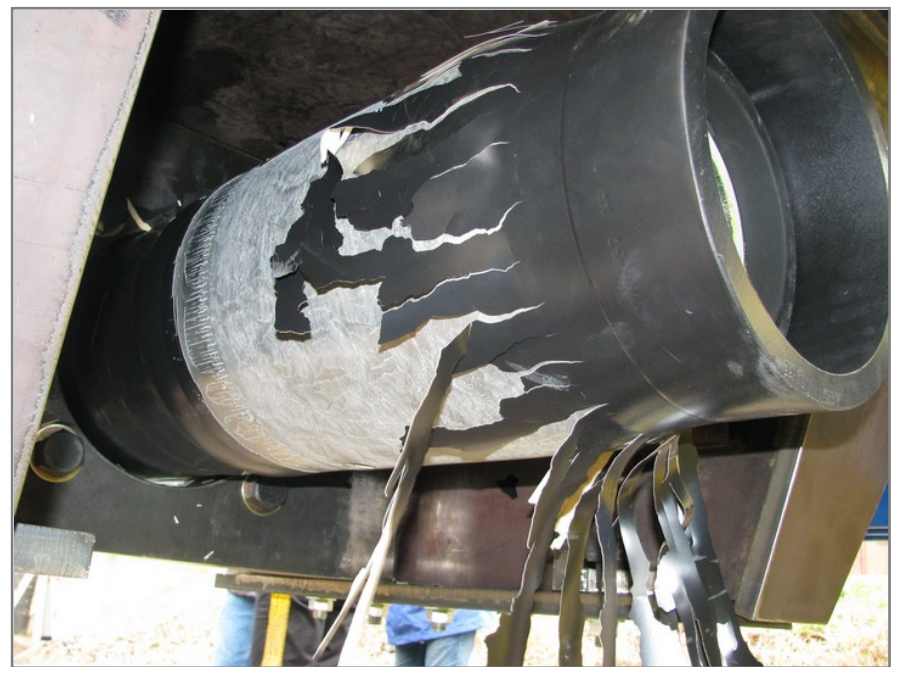

Figure 11. The push-back coupler deformation tube after the first impact

Two independent measurements of impact load were made for this test: (1) the load-displacement response for the load cell set mounted on the instrumented wall, and (2) the single load cell mounted at the end of the coupler extension (see Figure 8). The two measures of load were consistent with one another, as well as with the accelerometer data. Key result metrics from the first impact are as follows:

- Total stroke: $454 \mathrm{~mm}$ (17.9 inches)

- Push-back trigger force: about 2,970 kN (670 kips)

- Maximum force: 3,300 kN (740 kips)

- $\quad$ Energy absorbed: 1,300 kJ (960 ft-kips).

Figure 12 and Figure 13 show the test article after the second impact. The sliding lug has been pushed back about 10 inches. The bolts did not all fail completely on a plane parallel to the direction of motion. The three bolts on the left front of the sliding lug all appear to have sheared at roughly at a 45 degree angle through half of their thickness, as shown in Figure 14. There are also gouge marks on the facing surfaces of the support assembly, as shown in Figure 13, indicating that the sheared bolts scraped along the side of the support assembly as the sliding lug pushed back. In fact, it was not possible to separate the lug from the support assembly immediately after the test because of at least one protruding bolt surface.

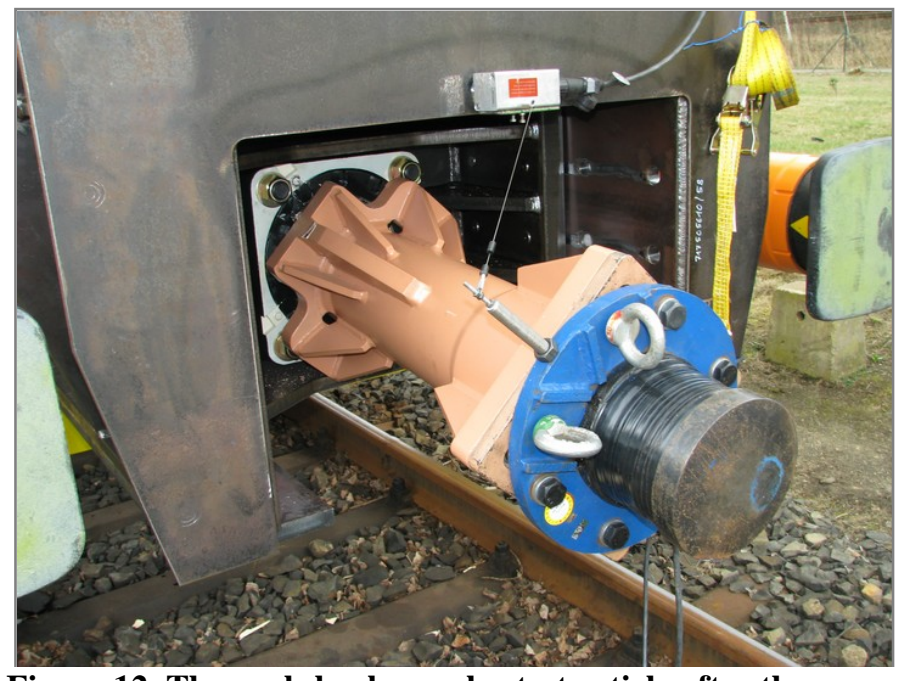

Figure 12. The push-back coupler test article after the second impact

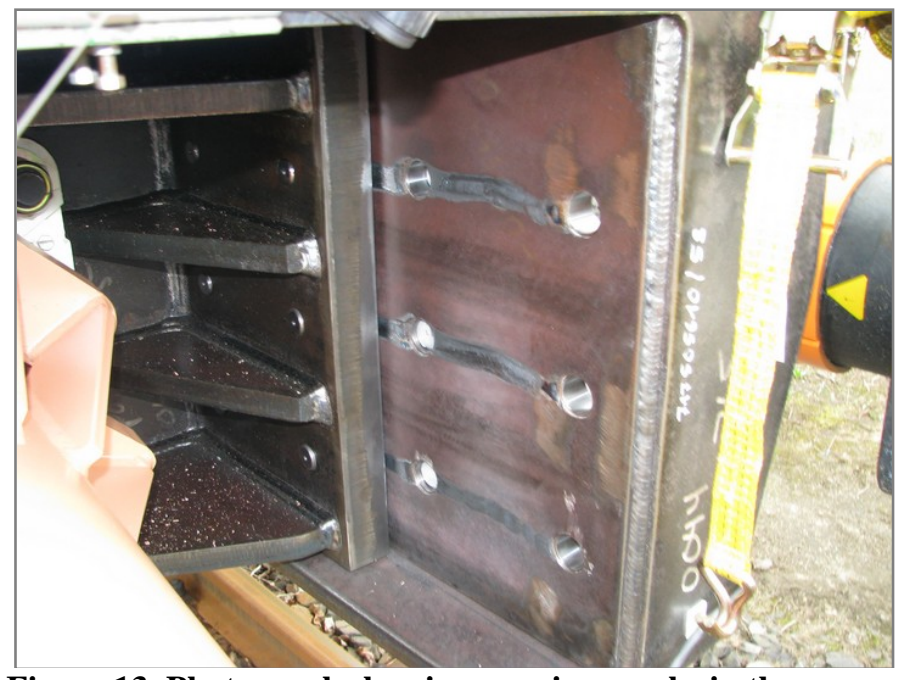

Figure 13. Photograph showing gouging marks in the coupler support assembly after the second impact

Figure 15 shows the measured load-displacement plot in which the load is taken from the load cell set on the wall and the displacement is taken from the string pot at the coupler extension. Key result metrics from the second impact are as follows:

This material is declared a work of the U.S. Government and is not subject to copyright protection in the United States. Approved for public release; distribution is unlimited. 
- Total stroke: $96 \mathrm{~mm}$ (3.8 inches), up to complete bolt fracture.

- Maximum force: 5,640 kN (1,270 kips).

- Energy absorbed: 165 kJ (120 ft-kips).

The push-back coupler test results indicate that the element meets component requirements:

a) Push-back trigger load: 2,970 kN (670 kips)

- Design minimum value: 2,670 kN (600 kips)

- Design maximum value: $3,560 \mathrm{kN}$ (800 kips)

b) Energy absorption: $1,300 \mathrm{~kJ}$ (960 ft-kips)

- Design minimum value, 810 kJ (600 ft-kips)

The exact value of the push-back trigger load is difficult to define because of dynamic effects, but it is certainly within the range of the required load.

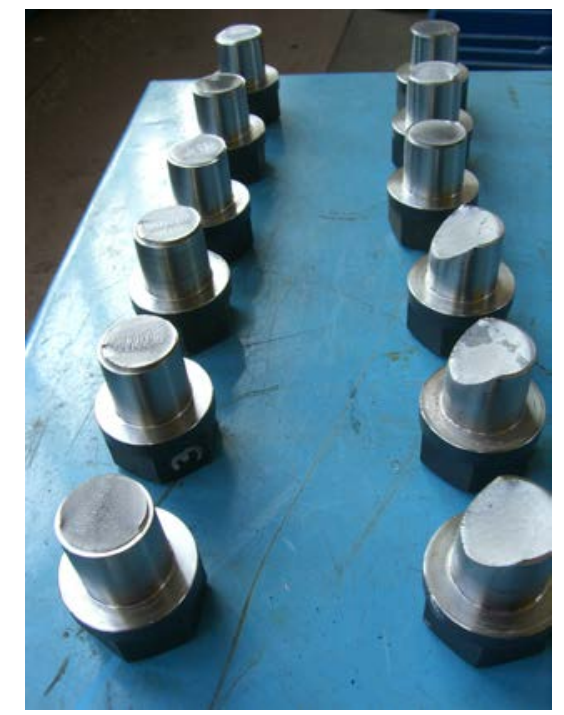

Figure 14. Photograph showing all twelve failed shear bolt heads; note three on bottom right that sheared nonuniformly

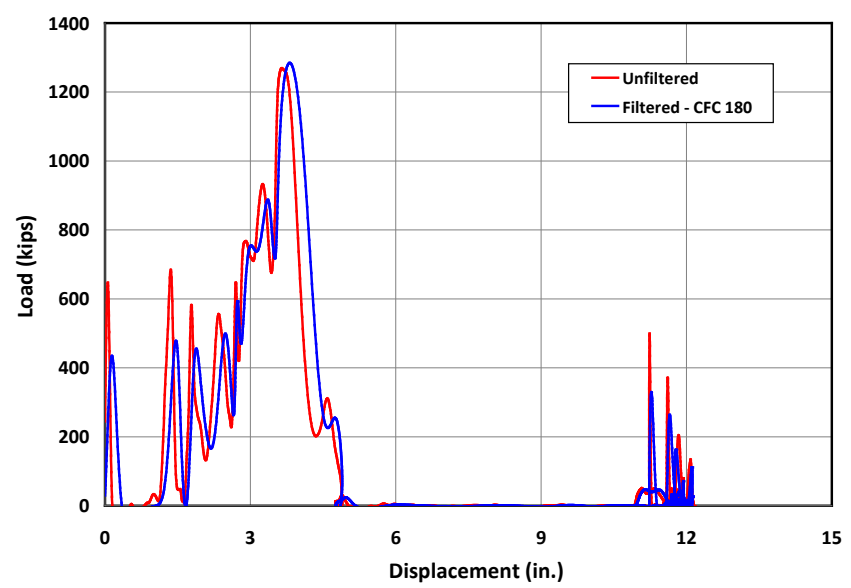

Figure 15. The load-displacement response measured for the second push-back coupler impact test (unfiltered and filtered at CFC 180)
The expectation was that the total shear bolt failure load would be about 4,700 kN (1,056 kips). The measured load corresponding to shear bolt failure was 5,640 kN (1,270 kips), which is $20 \%$ higher than the expected value. This may partly be due to dynamic effects, but could also be due in part to the non-uniform shearing of the three forward-left bolts.

The push-back coupler system is designed to permit pushback of the sliding lug by 14 inches to allow the deformable anti-climber to absorb energy. The lug moved back about 10 inches. It appears from Figure 15 that there was little resistance to push-back motion for the first five inches or so, and indications of some resistance at around 5 to 6 inches of push-back, with little resistance thereafter. This resistance may have been due to gouging of the non-uniformly sheared bolts (see Figure 13) or interference between the sliding lug and the support plates. The measured accelerations indicate that the vehicle pitched downward on initial impact but then oscillated without significant pitch after about 8 inches of stroke.

\section{Deformable Anti-climber}

Figure 16 shows a photograph of the deformable anti-climber test article, which is mounted to the load cell sets on the impact wall. The end of the impacting car is flat with no additional structure. Energy absorbing buffers were not used in this test, because no additional stroke was available beyond the design crush stroke. The impact speed of rail car in the single impact was $20.8 \mathrm{~km} / \mathrm{hr}(13.0 \mathrm{mph}), 0.8 \mathrm{~km} / \mathrm{hr}$ greater than the target speed.

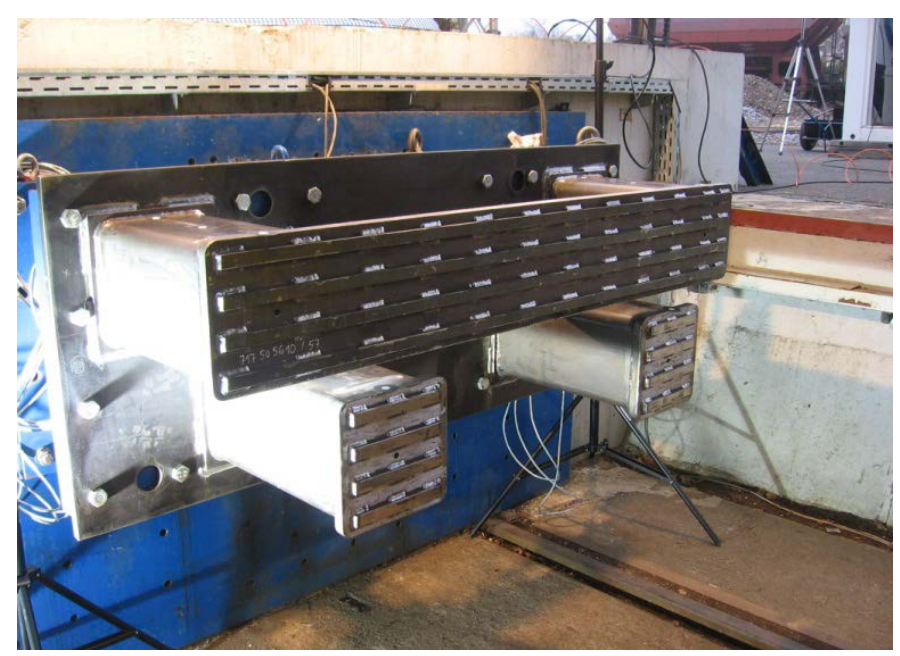

Figure 16. A photograph of the deformable anti-climber test article mounted on the impact wall prior to impact

Figure 17 and Figure 18 show the test article after the impact. The energy absorption capacity of the test article has essentially been exhausted. The deformation pattern is very symmetric with respect to the centerline. There are small areas of cracking, as evident in Figure 19, but these are isolated. Figure 20 shows the measured load-displacement plot, with the load taken from the load cell set on the wall and the

This material is declared a work of the U.S. Government and is not subject to copyright protection in the United States. Approved for public release; distribution is unlimited. 
displacement taken from a ruler on the car. They key result metrics from the test are as follows:

- $\quad$ Total stroke: $373 \mathrm{~mm}$ (14.7 inches)

- Maximum force: 5,960 kN (1,340 kips).

- Energy absorbed: 1,350 kJ (1,000 ft-kips).

All of the welds were inspected after the test and found to be intact.

The deformable anti-climber test results indicate that the element met both the component trigger load requirements and the energy absorption requirement:

a) Push-back trigger load: 3,650 kN (820 kips)

- Design minimum value: 3,560 kN (800 kips)

- Design maximum value: 5,340 kN (1,200 kips)

b) Energy absorption: 1,350 kJ (1,000 ft-kips)

- $\quad$ Design minimum value, $945 \mathrm{~kJ}$ (700 ft-kips)

The exact value of the push-back trigger load is difficult to define because of dynamic effects. The deformation is very symmetric and the individual tubes exhibit a classic accordion pattern.

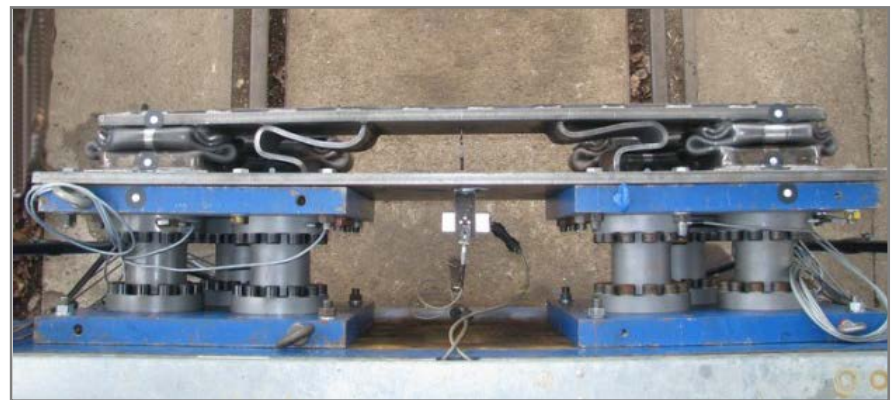

Figure 17. The deformable anti-climber test article after impact (top view)

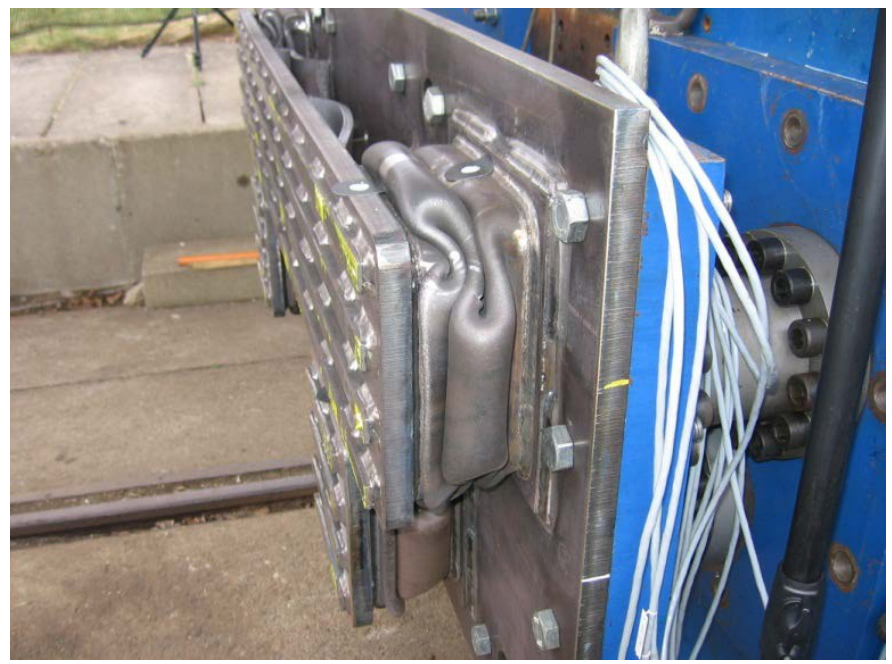

Figure 18. The deformable anti-climber test article after impact (side view)

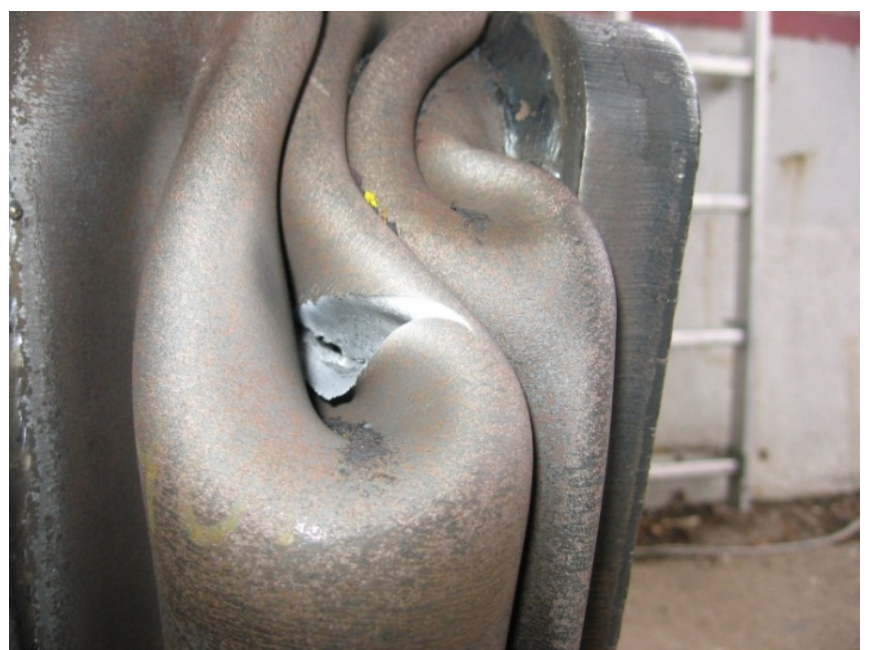

Figure 19. Photograph of a crack in the deformable anticlimber test article after impact

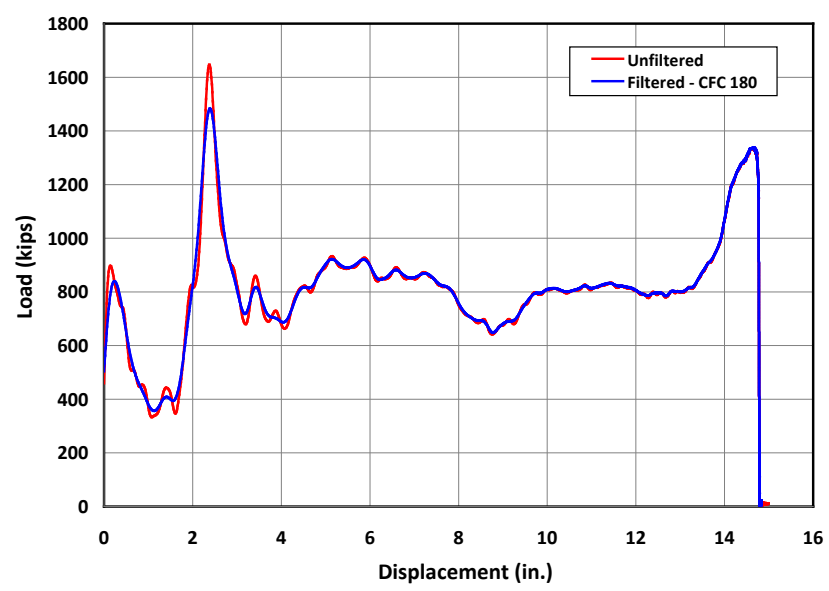

Figure 20. The load-displacement response measured for the deformable anti-climber test (unfiltered and filtered at CFC 180; displacement measured by laser/ruler)

\section{COMPARISON OF TESTS WITH PREDICTIONS}

The results of the dynamic tests were compared to the finite element analysis predictions of the behavior of the test articles.

\section{Push-back Coupler}

Due to the low impact speed for the first push-back coupler test, the push-back coupler system was tested in two stages: one stage to exhaust the push-back coupler stroke, and one stage to break the bolts. Because of this, in order to compare with the prediction for a single test, the force-displacement results for the two impacts must be combined into a single integrated curve. Figure 21 shows such a comparison. In this figure, the test results for the $1^{\text {st }}$ impact are plotted as measured. The results for the $2^{\text {nd }}$ impact have been shifted by the extent of permanent deformation predicted in the $1^{\text {st }}$ test - about 15 inches ( $\sim 18$ inches of deformation tube stroke minus $\sim 3$ inches of rubber spring elastic recoil).

This material is declared a work of the U.S. Government and is not subject to copyright protection in the United States. Approved for public release; distribution is unlimited. 


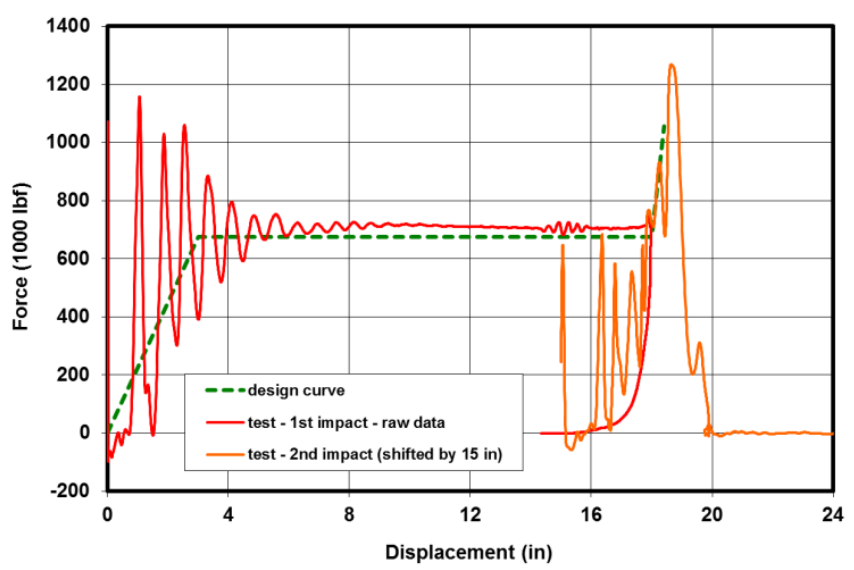

Figure 21. Comparison of measured force-displacement behavior with design curve

As is evident in the figure, there is good overall agreement between the design curve and the test results. In the figure, raw test data indicate a large oscillation, about $270 \mathrm{~Hz}$. This oscillation appears to be associated primarily with the rubber spring deformation and appears to dampen out quickly once the deformation tube begins to deform. However, the test results from both impacts capture the design intention reasonably well. The FE model predictions were also consistent with the design curve and the test data.

As noted earlier, model predictions of the force required to break the bolts are based primarily on the measured shear strength of the bolts -12 x 88 kips $=1056$ kips. The raw measured peak load associated with bolt failure is approximately 1,260 kips (see Figure 15), almost 20\% higher than the combined shear strength of the bolts. The $20 \%$ increase may partly be due to the dynamics of the bolt failure process; however, it is likely that much of the increase is due to the 'unclean' nature of the shearing off process for the left, forward set of three shear bolts (see Figure 14).

A better match between the test result and the design shear strength may have been achieved if additional care had been taken to ensure that the gap between the sliding lug and the side plate of the support assembly - across the shear plane of the shear bolt - was balanced across all of the shear bolts. The non-ideal shearing of these three bolts is more likely due to compressive stresses between the sliding surfaces that arose when the bolts were tightened. This, in turn, produced tensile stresses in these bolts that contributed to the observed fracture pattern.

\section{Deformable Anti-climber}

The measured force-displacement curve for the deformable anti-climber test is compared to the pre-test prediction curve in Figure 22. The predicted displacement for the measured impact speed of $20.8 \mathrm{~km} / \mathrm{hr}$ is 14.4 inches, as is indicated in the figure. The measured maximum displacement is approximately 14.9 inches. Overall, there is excellent agreement between the predictions and the test data. The minor difference between the measured and predicted displacement can be attributed to two factors:

- Over the first four inches of displacement, the predicted average load is approximately $740 \mathrm{kips}$, and the measured average load is approximately 680 kips. The shape of the test curve indicates that there is more compliance in the system than the FEA model predicts. This may be due to non-uniformities in the initial geometry of the structure, misalignment with the test vehicle, etc. It may also be due to a phase lag in the load cells. The build-up of load associated with impact of the two respective sets of crush tubes appear to be more gradual than the model predicts. This leads to an offset of about 0.5 inches or so in the displacements at which the peaks occur, and this additional compliance lowers the average load.

- Over the displacement range 4-12 inches, the predicted average load is approximately 840 kips, but the measured average load is only 800 kips. After the impact of the second set of tubes, all four tubes fold in a manner that is quite consistent with both model predictions and the results of quasi-static compression tests. The 40-kip difference between the predicted and average load can be attributed to differences between the modeled and actual hardening and failure behavior of the A572-50 material as well as imperfections in the initial geometry of the tubes. Buckling processes can be quite sensitive to geometrical imperfections, which would tend to lower the load required to fold the tube.

When both of these factors are added up, after 12 inches of crush, there is an additional 560 in-kips of kinetic energy that must be absorbed in the test. This extra energy is consistent with the extra 0.5 inches of crush occurring at an average force of 1,000 to 1,100 kips.

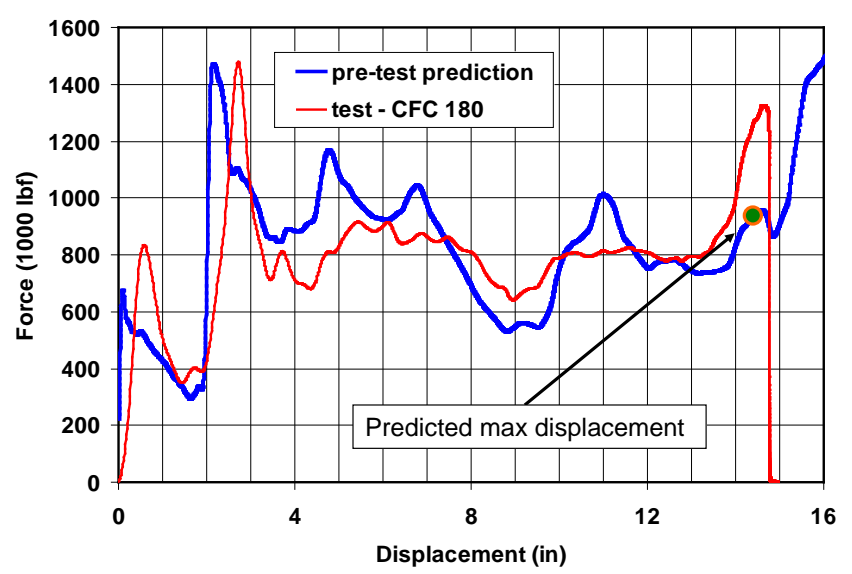

Figure 22. Comparison of measured force-displacement curve for the deformable anti-climber test with the pre-test prediction. The predicted displacement for the measured impact speed of $20.8 \mathrm{~km} / \mathrm{hr}$ is indicated

This material is declared a work of the U.S. Government and is not subject to copyright protection in the United States. Approved for public release; distribution is unlimited. 
In terms of deformation, it is most useful to compare the model predictions with test results for equivalent extents of displacement. Therefore, while the model predicted a final displacement of only 14.4 inches for the measured impact speed of $20.8 \mathrm{~km} / \mathrm{hr}$, the model predictions are compared with test results at a total displacement of 14.7 inches. These comparisons are shown in Figure 23-Figure 25.

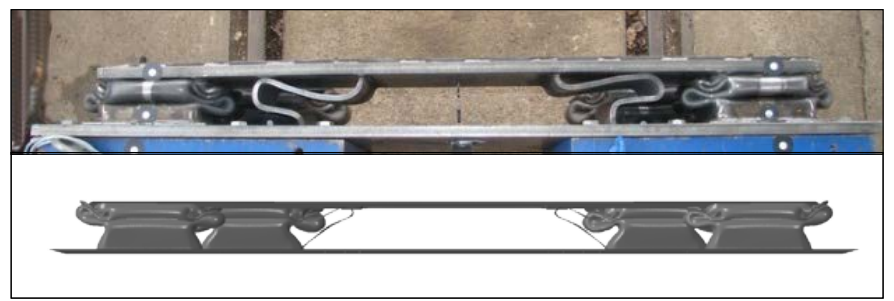

Figure 23. Comparisons of model prediction of test article deformation at 14.9 inches with post-test results: view from above test article

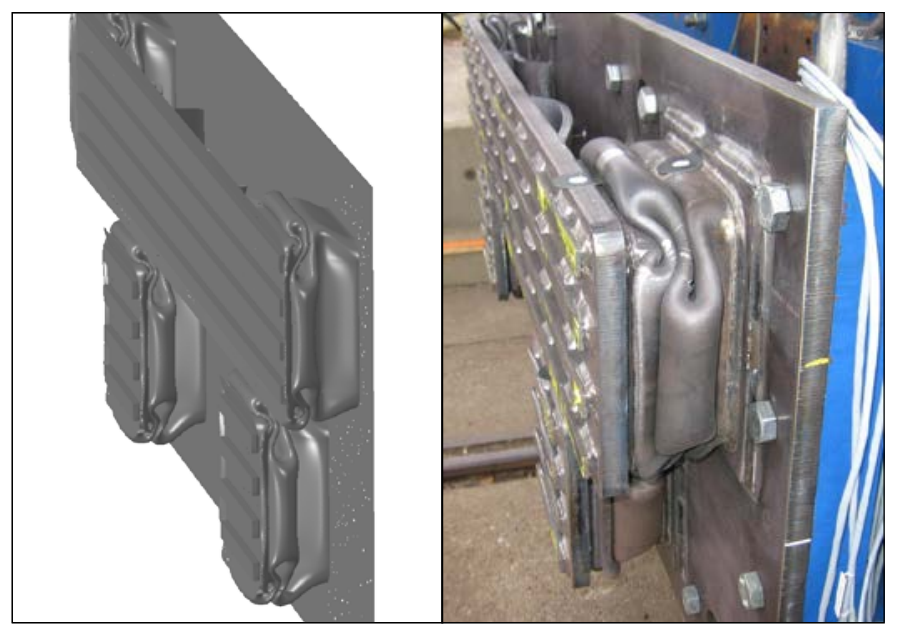

Figure 24. Comparisons of model prediction of test article deformation at 14.9 inches with post-test results: isometric view focusing on left upper crush tube

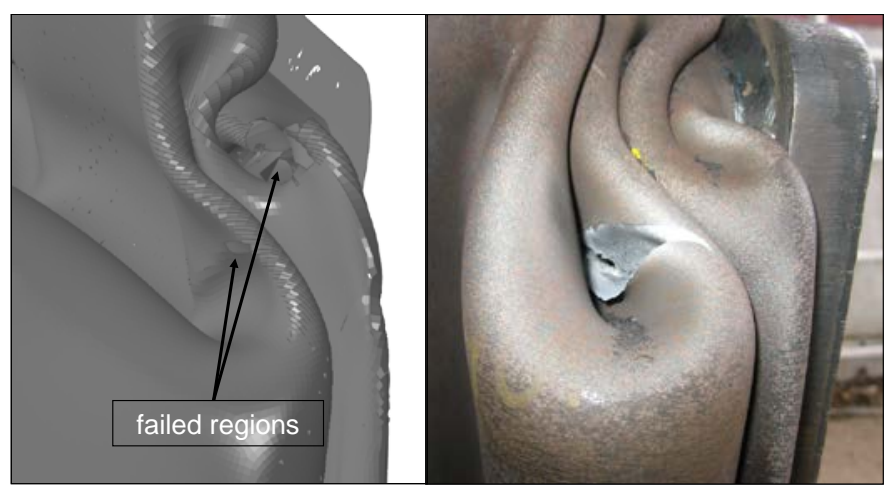

Figure 25. Comparisons of model prediction of test article deformation at 14.9 inches with post-test results: upper right tube showing localized fracture inside of a fold
The overhead view shown in Figure 23 indicates that the model captures the essential features of the deformation quite well. The predicted folding pattern of the tubes is identical to the actual pattern, with the exception that, in the model, the 'ears' that are formed on the sides of the tubes tend to be oriented more towards the impacted end of the tube than they actually are in the test. The most significant difference between the predicted and actual modes of deformation is that the angled support plates fold in a different manner. The model predicts the front of the plate to fold outwardly and the back of the plate to fold inwardly. The test result is just the opposite. This difference is not surprising, and is likely due to geometrical imperfections and/or pre-stresses in the plates due to welding. More importantly, it is unlikely that the direction of folding has a significant effect on the transmitted load.

The isometric view shown in Figure 24 presents a better view of the folded tube. Here again one can see the difference in the orientation of the side folds. Overall, however, the model captures the deformation mode quite well. The folding pattern observed dynamically is also quite similar to the folding pattern observed in the quasi-static crush test.

As expected, there were several locations of localized fracture. Without exception, these occurred in the corners of the crush tubes where severe plastic strain arises as the tube folds. Not only were such fracture locations predicted (see Figure 25), they were also observed in identical locations during the quasistatic tests. Given the extremely large plastic strain and complex deformation patterns (and therefore large triaxialities) that arise as the tubes crush, such localized fractures will occur despite the excellent inherent ductility of the A572-50 material. Moreover, these fractures do not appear to hinder the absorption of energy that occurs as the tubes fold.

\section{CONCLUSIONS \& NEXT STEPS}

The purpose of the testing program was to verify certain performance characteristics of the two crashworthy components relative to the design requirements. Overall the tests were successful in demonstrating the effectiveness of the two crashworthy components. Test results were consistent with model predictions both in terms of force-displacement behavior and modes of deformation. A few "lessons learned" during the program worth noting:

- The materials testing and crush tube testing were well worth the time and investment required. The tensile tests were relatively easy to do, and produced data that were invaluable to the FEA modeling component of the program. Likewise, the crush tube tests were completed relatively quickly and at relatively low cost, and allowed for a refinement in the design of the deformable anti-climber that prevented the much more costly dynamic impact test from failing. The FEA modeling that was undertaken as part of the crush tube test program also helped to guide the more complex FEA of the deformable anti-climber test article, which provided much confidence in the outcome going into the dynamic test.

This material is declared a work of the U.S. Government and is not subject to copyright protection in the United States. Approved for public release; distribution is unlimited. 
- The crush tube tests also aided in the decision to use four slots for the crush tube design rather than two slots, so as to minimize the peak in load associated with the impact of the second set of tubes.

- To ensure the proper impact speed was achieved, one or two speed test runs should have been conducted prior to the actual test.

As stated in the introduction, the objectives of the overall research program were to: (1) develop detailed designs for a push-back coupler and a deformable anti-climber; (2) develop test article designs for the components; (3) construct the test articles; and (4) conduct the component tests. These objectives were met: the crashworthy component designs met the design requirements and the resulting test articles were fabricated and performed as predicted by the computer simulations. Future plans include retrofitting these crashworthy components onto conventional locomotives and conducting full-scale dynamic impact tests.

The overridden locomotive involved in the Red Oak accident was compliant with the latest regulations, specifically AAR S-580. A push-back coupler and deformable anti-climber on the locomotive might have mitigated the severity of the collision, and possible saved the lives lost. When AAR S-580 was adopted, the technology for push-back couplers and deformable anti-climbers was not sufficiently mature. This research program endeavored to develop this technology further and provide the technical basis for including push-back couplers and deformable anti-climbers in future revisions of the AAR S-580 regulation.

\section{ACKNOWLEDGEMENTS}

This work was performed as part of the Equipment Safety Research Program sponsored by the Office of Research and Development of the Federal Railroad Administration. The Volpe Center planned, monitored, and evaluated the research. TIAX and its subcontractors developed, evaluated and tested the component designs. The authors appreciate the support and guidance offered by Kevin Kesler, Chief of the Equipment and Operating Practices Division, Jeff Gordon, Program Manager, Office of Railroad Policy and Development, John Punwani, Program Manager, Office of Railroad Policy and Development, and David Tyrell, Karina Jacobsen, and Benjamin Perlman of the Crashworthiness Team at the Volpe Center. The authors would like to thank Gabriel Amar of Taylor Raynauld Amar \& Associates for his contribution to the contract effort. A CAD model of an MP40 locomotive was provided by MotivePower. Drawings of the freight car were provided by TrinityRail. The authors would also like to thank Voith Turbo for donating a push-back coupler for use in impact testing. In addition, Voith Turbo provided custom-designed shear bolts and a speciallydesigned coupler shank, both of which were designed specifically for the program.

\section{REFERENCES}

[1] Tyrell, D., Severson, K., Marquis, B., Martinez, E., Mayville, R., Rancatore, R., Stringfellow, R., Hammond, R., Perlman, A.B., "Locomotive Crashworthiness Design Modifications Study," Proceedings of the 1999 IEEE/ASME Joint Railroad Conference, Institute of Electrical and Electronics Engineers, Catalog Number 99CH36340, 1999.

[2] National Transportation Safety Board , "Collision of BNSF Coal Train With the Rear End of Standing BNSF Maintenance-of-Way Equipment Train, Red Oak, Iowa, April 17, 2011," NTSB Railroad Accident Report, NTSB/RAR-12/02, PB2012-916302, April, 2012.

[3] Mayville, R., Stringfellow, R., Johnson, K., Landrum, S., "Crashworthiness Design Modifications for Locomotive and Cab Car Anticlimbing Systems," US Department of Transportation, DOT/FRA/ORD-03/05, February 2003.

[4] Llana, P., Stringfellow, R., "Preliminary Development of Locomotive Crashworthy Components," American Society of Mechanical Engineers, Paper No. JRC201156104, March 2011.

[5] Llana, P., Stringfellow, R., "Preliminary Finite Element Analysis of Locomotive Crashworthy Components," American Society of Mechanical Engineers, Paper No. RTDF2011-67006, September 2011.

[6] Association of American Railroads, AAR S-580 Standard, "Locomotive Crashworthiness Requirements," adopted December 2004, revised 2008.

[7] The American Public Transportation Association, APTA SS-C\&S-034-99, Rev 2, Standard for the Design and Construction of Passenger Railroad Rolling Stock”, 2006.

[8] Code of Federal Regulations, Title 49, Part 229, "Railroad Locomotive Safety Standards".

[9] The American Public Transportation Association, APTA RP-C\&S-XXX, Recommended Practice for Push-back Couplers in Passenger Rail Equipment, draft as of 7/1/08.

This material is declared a work of the U.S. Government and is not subject to copyright protection in the United States. Approved for public release; distribution is unlimited. 